Meta

Journal des traducteurs

Translators' Journal

\title{
On Describing Similarity and Measuring Equivalence in English-Spanish Translation
}

\section{Marlén Izquierdo}

Volume 59, numéro 1, avril 2014

URI : https://id.erudit.org/iderudit/1026474ar

DOI : https://doi.org/10.7202/1026474ar

Aller au sommaire du numéro

Éditeur(s)

Les Presses de l’Université de Montréal

ISSN

0026-0452 (imprimé)

1492-1421 (numérique)

Découvrir la revue

Citer cet article

Izquierdo, M. (2014). On Describing Similarity and Measuring Equivalence in English-Spanish Translation. Meta, 59(1), 140-159.

https://doi.org/10.7202/1026474ar

\section{Résumé de l'article}

Le présent article rend compte d'une étude descriptive qui analyse de manière empirique la notion d'équivalence dans le domaine de la traduction. Pour ce faire, l'analyse se concentre sur les similitudes et les différences, considérées comme éléments constitutifs de toute relation d'équivalence, entre les textes d'origine et les textes d'arrivée. Dans ce cas précis, les textes d'origine sont des compléments circonstanciels anglais G-P (pour Gerund-Participle [gérondif]) et les textes d'arrivée, leurs équivalents de traduction espagnole que l'on trouve dans ce qu'il est convenu d'appeler « le corpus parallèle ACTRES ». L'étude est interdisciplinaire dans le sens où elle puise dans l'analyse fonctionnelle contrastive et les études de traduction descriptives, selon une approche par corpus. Elle révèle différents types de similitudes entre les compléments circonstanciels anglais G-P et leurs équivalents espagnols, qui sont décrits en termes fonctionnels, prenant compte de la fonctionnalité, de l'interface sens-forme et de la fréquence d'usage. Les paramètres descriptifs suivis ont entraîné la création d'un système de classification servant à mesurer l'équivalence entre les objets d'étude.
Ce document est protégé par la loi sur le droit d'auteur. L'utilisation des services d’Érudit (y compris la reproduction) est assujettie à sa politique d'utilisation que vous pouvez consulter en ligne.

https://apropos.erudit.org/fr/usagers/politique-dutilisation/ 


\title{
On Describing Similarity and Measuring Equivalence in English-Spanish Translation*:
}

\author{
MARLÉN IZQUIERDO \\ Universidad del País Vasco/Euskal Herriko Unibertsitatea, Vitoria-Gasteiz, Spain \\ marlen.izquierdo@ehu.es
}

\begin{abstract}
RÉSUMÉ
Le présent article rend compte d'une étude descriptive qui analyse de manière empirique la notion d'équivalence dans le domaine de la traduction. Pour ce faire, l'analyse se concentre sur les similitudes et les différences, considérées comme éléments constitutifs de toute relation d'équivalence, entre les textes d'origine et les textes d'arrivée. Dans ce cas précis, les textes d'origine sont des compléments circonstanciels anglais G-P (pour Gerund-Participle [gérondif]) et les textes d'arrivée, leurs équivalents de traduction espagnole que l'on trouve dans ce qu'il est convenu d'appeler «le corpus parallèle ACTRES ». L'étude est interdisciplinaire dans le sens où elle puise dans l'analyse fonctionnelle contrastive et les études de traduction descriptives, selon une approche par corpus. Elle révèle différents types de similitudes entre les compléments circonstanciels anglais G-P et leurs équivalents espagnols, qui sont décrits en termes fonctionnels, prenant compte de la fonctionnalité, de l'interface sens-forme et de la fréquence d'usage. Les paramètres descriptifs suivis ont entraîné la création d'un système de classification servant à mesurer l'équivalence entre les objets d'étude.
\end{abstract}

\begin{abstract}
This article reports on a descriptive translation study that attempts to examine the notion of equivalence in translation in an empirical manner. In order to do that, the analysis focuses on the similarities and differences, considered as the components of any relation of equivalence, between the source texts and the target texts. In this particular case, the source texts are English Gerund-Participle (G-P) Adjuncts, and their target texts, the Spanish translational options found in so-called "ACTRES parallel corpus." The study is interdisciplinary as it draws from contrastive functional analysis and descriptive translation studies, from a corpus-based approach. The study reveals different types of similarities between the English G-P Adjuncts and its Spanish equivalents, which are described in functional terms, taking into consideration functionality, meaning-form interface and frequency of usage. The descriptive parameters followed have prompted a grading system for measuring equivalence between the objects of study.
\end{abstract}

\section{MOTS-CLÉS/KEYWORDS}

équivalence, similitude, complément circonstanciel, traduction, contraste equivalence, similarity, adjunct, translation, contrast

\section{Introduction}

Interdisciplinarity seems to have become a benchmark of descriptive, linguistic studies of an application-oriented nature. This is indeed the case within the field of descriptive translation studies (DTS), as a great deal of research draws on linguistics and computation. The former may display a wide range of approaches among which contrastive analysis $(\mathrm{CA})^{1}$ is the one advocated for here. The latter has contributed to 
develop a powerful tool, namely, corpora. The fruitful alliance of CA and DTS has been empirically proved by the Análisis Contrastivo y Traducción English-Spanish (ACTRES) research group, which today has dealt with an extensive array of crosslinguistic phenomena at different levels of linguistic analysis. ${ }^{2}$ The use of linguistic corpora has made it possible to combine both disciplines in order to carry out case studies where much is learnt with regard to the languages involved in a translation process, as much as on the translation product, all of it paving the way for future applications. The benefit of such a combination is not only observed in actual, empirical research, but also in the migration of concepts, methods, and terms between one another. As a matter of fact, the current study is an instance of this, as, although it is mainly a descriptive translation study, one of the notions under examination derives from contrastive functional analysis (Chesterman 1998) and the methodology adopted has been designed by the ACTRES research group for contrastive-and-translation joint studies, taking contrastivist Krzeszowski's proposal as a basis (Krzeszowski 1990).

As such, this study seeks to observe the degree of (assumed) similarity between English Gerund-Participle (G-P) constructions and their Spanish equivalents. The concept of similarity is to be understood in Chesterman's sense as consisting of both sameness and differences (Chesterman 2007). The term equivalent is considered as the linguistic correspondence of a meaningful unit in text A, namely the source text (ST), as shown by its translation or target text (TT) in Spanish. ${ }^{3}$ In other words, this correspondence entails the relation between the ST and the TT, which is traditionally referred to as equivalence. It is on the assumption that the ST item or meaningful unit and its corresponding TT achieve the same value, that a 'tertium comparationis' (TC) is established for us to contrast one with another. Such an equal value can be attained at various levels, with possible overlaps, so that the level where the ST and TT items share the most would determine what kind of TC underpins the relation of similarity/equivalence. The hypothesis underlying this piece of research is that there is indeed certain degree of assumed similarity - at a functional level - between one type of English G-P constructions and the Spanish Gerund constructions, but there are differences as well, which are to be revealed by the translations themselves. Two main questions arise: firstly, what are the differences displayed in a cross-linguistic relation conceived of as equivalent - as is translation - and, secondly and consequently, to what extent is equivalence attained? The first question requires the observation of the various translational options offered by Spanish to render the meanings of the original English resource, which can be done by gathering a repertoire of corpus-based, cross-linguistic equivalents. The second question hints at the possibility of measuring equivalence, a much-debated notion of which theoretical accounts outnumber descriptive examinations of its materialization.

In order to answer the first question, we focus our attention on language use, considering issues such as meaning-form interface and frequency of usage. The second question will be addressed in terms of two possible kinds of similarity, as well as on the syntagmatic shifts observed between ST and TT. 


\section{Cross-linguistic similarity and equivalence}

These two terms intertwine with one another. As a matter of fact, the former has long been considered a condition for the latter. Its embedding nature remains, although not so much as a condition for translation equivalence but as a component of it. This, however, has taken various approaches to equivalence to become clear, after having shifted the focus of attention to the TT and viewing equivalence "as the relationship which actually obtains between the translation and the source text: an empirical, rather than an ideal phenomenon, open to description" (Malmkjaer 2005: 15). It is, therefore, by describing actual instances of translation that the type of similarity between ST and TT can ever be identified, and, consequently, its degree of equivalence measured.

As indicated above, the idea of similarity was once taken as a condition for two texts to be considered equivalent to each other. One of the staunchest defenders of such an idea authors an early linguistic approach (Catford 1965), whereby interest lay on the ST, to which the TT had to be as similar as possible. Catford's approach was rather formal, as he was not preoccupied with meaning, but with the possibility for source and target language items "to be interchangeable in a given situation" (Catford 1965: 49). This approach is now clearly unable of dealing with equivalence. However, Catford already realized that the correspondence between terms or texts from two languages will be approximate, as "it is rarely the case that both pair members will be relatable to all of the same features of the situation" (Catford 1965: 49), ${ }^{4}$ which hints at the gradable nature of similarity and, hence, equivalence. This gradation is also suggested in Nida's approach, for whom a translation might aim at either so-called formal equivalence or dynamic equivalence (Nida 1964). Whereas the former is attained through - substantially formal - similarity of message in source and target languages, the latter seeks to (re)produce the same effect within the target culture. However, on the assumption that meaning and form trigger each other and altogether carry out a function in a given context, this division cannot be clear-cut. Rather, the degree of decoding effort might well mirror that of similarity inversely. In other words, the lesser the effort to (de)code the message, the greater the similarity.

An asset of Nida's account is its transitory position from a linguistic to a descriptive approach to equivalence. One problem with his proposal, however, is that it implies two contradictory orientations, as formal equivalence is source-oriented, whereas dynamic equivalence is target-oriented. The fact that both types of equivalence are actually the extremes of a continuum means that they necessarily move in the same direction, whatever that might be. Consequently, another approach that sheds light on the directional nature of equivalence is necessary, the roots of which are to be found in Toury's theory. Following Toury (1995), translations pertain to one pole only, namely, the target culture. As such, it is after a ST has been rendered into a target language that we can talk about translation and, therefore, equivalence. Directional equivalence is created by the translator, as opposed to the natural equivalence advocated for within the linguistic paradigm, and whereby correspondence was ideally conceived prior to two languages being engaged in an act of translation (Pym 2007). If we accept that equivalence is created by translators, its analysis demands the examination of actual language use. Such a descriptive approach to translation equivalence needs nourishing from neighbouring disciplines like CA and 
corpus linguistics (CL). It is believed that these will provide a framework for empirical analysis whose results will contribute to theory construction.

When handling equivalence in an empirical manner, the following aspects need examining: the meaning-form interface, frequency and types of similarities observed as well as the differences found. How can all these components of similarity be analyzed? Or in other words, which tool provides instances of directional equivalence in actual language use? To answer these questions, it is essential to first deal with another one, namely: on what grounds is similarity attained? Contrastive Functional Analysis (Chesterman 1998) provides an answer: there exists a TC whereby ST and TT share like with like, equal values that make it possible to contrast them in search of similarities and differences. On the other hand, a parallel corpus is a suitable tool from which equivalent resources will be extracted. By parallel corpus, I understand a translation corpus comprising original texts in one source language (SL), and their translation into a target language (TL). The language pair I am concerned with in this paper is English as SL and Spanish as TL.

\section{English Gerund-Participle and Spanish Gerund Adjuncts in contrast}

On the assumption that the English Gerund-Participle (G-P) (Huddleston and Pullum 2002) and the Spanish Gerund (G) share equal, functional values, a corpusbased, contrastive analysis was conducted in order to map out similarities and differences with regard to their functionality (Izquierdo 2008). Thereby, the underlying TC, which is maintained in the current analysis, is functional equivalence. The insights gained from this previous study brought to light a wider array of functions on the part of the English resource as opposed to its Spanish counterpart, which is useful information for future translation applications. This paper focuses, however, on one type of English G-P constructions with which the Spanish G seems to share the greatest degree of similarity, namely, G-P and G Adjuncts (Izquierdo 2008: 249). Both constructions express the same range of circumstantial meanings in either language, with minor differences in terms of frequency of realization.

With flexibility being a norm of language, nonetheless, it is rather unlikely to think that any English G-P Adjunct would always be translated into Spanish by means of a G Adjunct. Not only is this thought motivated by the fact that one form might convey several meanings, circumstantial or of other kind, but also because one meaning might be conveyed by various resources, both within and across languages. Since translators have to render in the TL the meaning expressed by a ST item, the question is which other resources translators use in Spanish when they come across an English G-P Adjunct? And most importantly, how similar are these TT items with regard, not only to the ST item alone, but also to the assumed equivalent, namely, the G Adjunct? I am, thus, looking at two types of similarity. On the one hand, I deal with convergent similarity, as it exists between the assumed equivalents. On the other hand, alternative translational options would display so-called divergent similarity (Chesterman 2007), as will be further explained (see section 6).

A terminological clarification needs to be done before the method is described. I follow Chesterman's view that similarity comprises both sameness and difference. However, while the above-mentioned scholar establishes a parallel between samenessequivalences and difference-shifts (Chesterman 2005: 27; 2007: 56), I find it mislead- 
ing to assume that equivalence rests on the sameness side, as empirical observation reveals that some translational options that clearly imply a shift do hold an equivalence relation with their STs (see section 6).

\section{Methodology}

This section is devoted to the method of the study, paying special attention to the tools used, the criteria for analysis followed and the procedural stages.

The method adopted is inductive as I expect data to answer my initial questions. As such, actual translations of English G-P Adjuncts into Spanish have been extracted from the so-called ACTRES Parallel corpus (Izquierdo, Hofland and Reigem 2008), which has been managed with the Corpus WorkBench system (CWB) and is accessed through a Web interface using the Corpus Query Processor (CQP). ${ }^{5}$ P-ACTRES contains source English texts and their translation into Castilian Spanish. All the texts have been aligned at the sentence level using TCA2 (Izquierdo, Hofland and Reigem 2008). This version of the alignment program lets the researcher check whether its suggestions are correct so as to guarantee 100\% accuracy. Most of the concordances retrieved from the corpus display a 1-1 alignment pair although multiple matches crop up as well (1-n or n-1, even n-n matches).

Linguistic corpora provide instances of language use that need functional interpretation. Consequently, a set of criteria has been established in order to analyze the data in terms of functional equivalence, as this is the TC that will let us contrast the translations with their STs, as well as among one another.

a) The first parameter to keep in mind is semantic function. In particular, I will consider whether the TT keeps the function realized by its corresponding source counterpart. Keeping the TC in mind, I would hypothesize that if a TT does not keep the source semantic function, the degree of equivalence tends to decrease;

b) Somehow intertwined with this criterion is the meaning-form interface, which will also shape data interpretation. With regard to this, I will look into regularities as well as deviations in meaning that a given grammatical resource might imply by considering a) how "close or far" in the syntagmatic axis this resource is, respective of the ST equivalent and other translational options, and b) the possible reasons why translations display these phenomena. Syntagmatic issues will be dealt with in terms of rank-shifts in translation. In principle, the notion of shift is understood in Venuti's terms (2002), whereby it is the textual result of a strategy deployed by translators as a necessary means to solve a problem, without it being a resource that overrides similarity completely;

c) A third criterion for analysis is frequency or how often a given translational option is used, as this parameter sheds light on usage and functionality preferences. If TTs had to be represented on a frequency axis, the two extremes would fluctuate from recurrent to peripheral equivalents.

The method unfolds in four stages, adapted from ACTRES proposal for corpusbased, contrastive-and-translation joint studies.

The first stage concerns the selection of the data. Entering as input query in P-ACTRES any verb ending in -ing, an initial population of over 12,000 concordances was retrieved. These data have been sorted manually, in order to isolate only those STs that contain a G-P Adjunct, resulting in a final sample of 3,475 parallel concordances. It is on these data that the following stages have been undertaken. 
Secondly, there is a description phase in which the STs are semantically classified. According to the data, a list of ten semantic functions have been found, whose frequency of realization is illustrated in Table 1.

TABLE 1

Semantic functions of ST

\begin{tabular}{|c|c|c|c|}
\hline $\begin{array}{l}\text { Semantic } \\
\text { function }\end{array}$ & Occurrences & Percentage & Example \\
\hline Time & 1,285 & $37 \%$ & $\begin{array}{l}\text {..take a deep breath and while doing this pull your } \\
\text { shoulder blades together }\end{array}$ \\
\hline Process & 834 & $24 \%$ & Using a handkerchief I moved the papers slightly \\
\hline Elaboration & 403 & $11.6 \%$ & $\begin{array}{l}\text { Abasio dismounted and carefully tied his horse, } \\
\text { taking his time about it so they could get a good look at } \\
\text { him, then went close enough... }\end{array}$ \\
\hline Result & 331 & $9.5 \%$ & $\begin{array}{l}\text { The structure of family life has also changed, making } \\
\text { it often impossible to live... }\end{array}$ \\
\hline Cause & 211 & $6.1 \%$ & $\begin{array}{l}\text {..the book is in my opinion excellent, and the } \\
\text { principles being absolutely sound can easily be applied }\end{array}$ \\
\hline Concession & 210 & $6.1 \%$ & In spite of being reminded, will keep forgetting... \\
\hline Purpose & 122 & $3.5 \%$ & I've just arrived from the North looking for work \\
\hline Illocution & 32 & $0.9 \%$ & $\begin{array}{l}\text { We discourage professional colleagues from } \\
\text { attempting to express concerns behind parents' backs, } \\
\text { or using jargon, preferring... }\end{array}$ \\
\hline Condition & 31 & $0.8 \%$ & If using a single flower, you could take.... \\
\hline Place & 16 & $0.5 \%$ & $\begin{array}{l}\text { The skill in hypothesis is in taking the person back } \\
\text { to... }\end{array}$ \\
\hline TOTAL & 3,475 & $100 \%$ & \\
\hline
\end{tabular}

Describing in detail the realization of these functions (Izquierdo 2008) is beyond the scope of this study. Nonetheless, this classification is necessary so as to identify the semantic match between TT and ST. This is, thus, taken as background information that will help describe similarity in a contrast stage, as will be explained (see sections 5 and 6).

There is a third stage, here referred to as juxtaposition, which is devoted to identifying all the TTs that hold an equivalence relation with the original G-P Adjuncts. Figure 1 shows the repertoire of TTs ordered per frequency of occurrence:

\section{FIGURE 1}

\section{Spanish Translational Options of English G-P Adjunct}

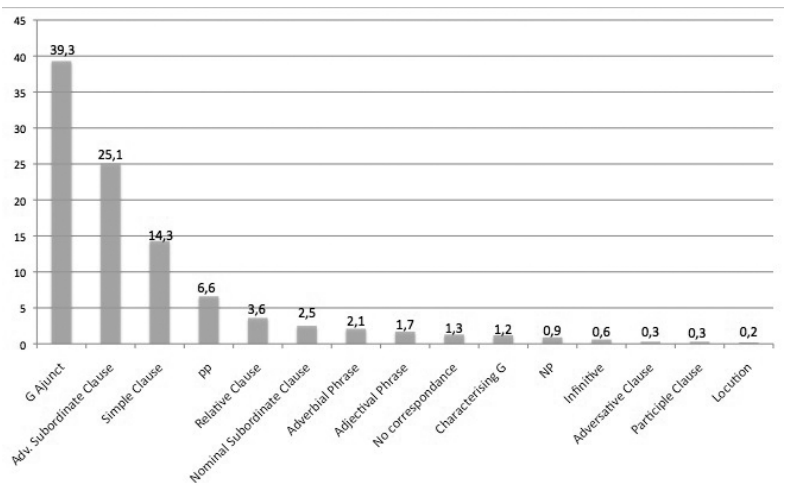


One of the translational options has been labeled "no correspondence," as there are certain STs for which no TT has been rendered. This phenomenon has been identified in the translation of seven out of ten semantic functions, apart from cause, condition and place. Far from being impossible to (de)code these STs, it is believed that translators could choose not to translate such instances for various reasons; a linguistic one might well be the semantic complexity that this type of resource entails, which leads the translator to ignore it altogether so as to go on with their task. This, in turn, might be related to a practical reason as imposed by the translation brief, whereby the translator needs to comply with a word limit or deadlines amongst other requirements. While this is definitely a translational option, it clearly is not an equivalent, and that is why I have not considered it as exemplifying any kind of similarity.

The fourth and last stage has been labeled contrast, as it implies comparing every type of TT with the STs, as well as establishing some kind of comparison between the different TTs observed. Such a contrast requires a great deal of interpretation based on the criteria mentioned above.

It is here where the different types of similarities have been identified, observing two main trends. On the one hand, the most frequent TT displays so-called convergent similarity, as this is the a priori assumed equivalent for which the highest degree of equivalence - and fewest differences - were expected. On the other hand, there is a great deal of other TTs that bring to light divergence similarity. I have decided to comment upon each type of similarity - convergent versus divergent - separately, so as to isolate idiosyncrasies of functional equivalence. This is just a methodological decision that should not imply that they are drawn apart; in fact, both belong to the same continuum of dynamic equivalence.

\section{Convergent similarity}

According to Chesterman, "convergent similarity [...] starts with a situation in which two (or more) entities exist, and the perception [...] of a similarity between them" (Chesterman 2007: 61). Such a perceived similarity, which triggered the corpus-based, contrastive functional analysis I referred to above (Izquierdo 2008), has materialized in the actual usage of the $G$ Adjunct as the most recurrent equivalent of source G-P Adjuncts. Both resources were assumed to converge into the same function, namely, the realization of circumstantial meanings, and data show this has been the case. On closer examination, however, certain shades of meaning crop up, which requires further interpretation of resource usage, as this could help measure the actual degree of equivalence held.

With regard to the first criterion for analysis (see section 4), the G Adjunct is equivalent to any of the semantic functions of the G-P Adjunct, although it is not the most frequent in all of them. It is the second most recurrent TT of STs that convey elaboration (19.1\%), cause (23.7\%), concession (5.7\%), purpose (15.5\%) and condition $(9.7 \%)$, while it comes in fourth position as the translation of G-P s that express place $(12.5 \%)$.

A second criterion concerns the meaning-form interface, which in this particular case focuses on regularities and/or differences between the Spanish G Adjunct as equivalent to English G-P Adjuncts comprising, or not, a semantics-bearing intro- 
ductory particle. Frequency information is bound up with this aspect of usage, so I will comment on both together. The data reveal an outstanding recurrence of the G Adjunct as equivalent to the English resource when it is bare, i.e., when there is no introductory particle. As such, this option ranks first in all semantic functions with the exception of purpose, where it occupies the second position (15.5\%), and place, for which no single realization has been found. On the contrary, translators seem to favour resources, other than the assumed equivalent, when the ST meaning is expressed by a G-P Adjunct equipped with a particle (Part_G-P Adjunct). To provide an example, while the $G$ Adjunct is more frequently used as equivalent for time, elaboration, and cause bare G-P Adjuncts (example 1), it is rather peripheral when those same meanings are conveyed by means of a Part_G-P Adjunct (example 2).

(1) a. I stood up anxiously, wanting to escape Cause bare G-P Adjunct

b. Me levanté nervioso, deseando huir de allí G Adjunct

(ACTRES Parallel Corpus)

(2) a. He had busted an old hippie for lying. Cause Part_G-P Adjunct

b. Había humillado a un viejo hippy por haberle mentido SubAdv - Inf clause

(ACTRES Parallel Corpus)

On the other hand, some G Adjuncts have been observed to deviate semantically from the English resource, that is, the TT expresses a meaning different from its ST, as seen in example (3).

(3) a. [...] where the eggs hatched and the larvae developed into maggots, eating right into his head Result bare G-P Adjunct

b. [...] las larvas se metamorfosean en gusanos y se alimentan penetrando en el interior de la cabeza

Process G Adjunct

(ACTRES Parallel Corpus)

This type of semantic deviation is common to almost all the semantic functions, except for concession and condition. Even though the degree of semantic deviation in the remaining functions is not very high, it is worth the analysis. From the point of view of the TL, the usage of the G Adjunct is acceptable; in non-translated Spanish, Gerund constructions belong to the syntagmatic axis for expressing circumstantial meanings, which might be nevertheless conveyed by other items as will be seen (see section 6). Yet, its outstanding recurrence might stem from the effect of perceived similarity. From a contrastive point of view, Tognini-Bonelli would have referred to this translation pair as "complete functional equivalents" (Tognini-Bonelli 2002). However, total equivalence is rarely - if ever - possible; on occasions, subtle semantic deviations might occur, as we have observed, meaning that the referential content of the equivalence relation is not the same, which would diminish the actual degree of functional equivalence attained. 
A possible explanation for this deviation is the ambiguity, or rather, indeterminacy (Kortmann 1991) that characterizes both English and Spanish Adjuncts. Sometimes, the same resource might convey more than one meaning, both of which are open to interpretation. This is especially the case when the Adjunct lacks an introductory particle that clarifies the semantic content. In relation to this, it might turn out explanatory to mention that the majority of STs conveying condition and concession comprise such a particle, without leaving room for ambiguity. In other words, the bigger the effort to map out the function expressed by the ST, the lower the degree of equivalence the TT is likely to display.

Overall, the degree of equivalence between convergent equivalents is fairly high. As far as the English G-P Adjuncts and the Spanish G Adjuncts are concerned, they both express the same types of meaning, even with fairly similar frequencies; for that, they occupy the same position in the syntagmatic axis of either language as nonfinite, adverbial sentences, and they both have similar textual effects, such as ambiguity. Out of this basis of sameness, differences arise, though, as not always do they preserve the semantic function in a relation of translation, which affects the degree of real equivalence attained.

\section{Divergent similarity}

Data bring to light the anisomorphic nature of equivalence, as materialized in a wide repertoire of translation equivalents, which would have been hard to identify prior to the mere act of translating. Instead, all these equivalents have been created by the translator (Chesterman 2007: 61). As many as thirteen different resources are functionally similar to the English G-P Adjuncts, although their degree of similarity varies, as will be seen. With regard to the frequency of usage of each resource, a two-tier classification can be suggested: recurrent versus peripheral equivalents. Being very frequent is not synonymous with being the most similar in function, though, as closer examination has revealed (see section 6.2.). Let us look in detail at the recurrent equivalents first.

\subsection{Adverbial Subordinate Clause (SubAdv)}

This resource has been used for translating any of the semantic functions realized by the ST. When this conveys cause (48.8\%), concession (77.1\%), purpose (56.2\%), condition (83.9\%) and place (43.75\%), a SubAdv is even preferred to the G Adjunct, while it ranks second as a translational option when it comes to translating time (23\%) and process (13.9\%) meanings, as illustrated by the following example (4):

(4) a. I retrieved my coat and stepped outside into the cold, irritated and disappointed, watching the snow fall. Part_G-P Adjunct - Time

b. Fui en busca de mi abrigo y salí a la fría noche, irritado y decepcionado, mientras contemplaba cómo caía la nieve.

SubAdv - Time 
On the other hand, the SubAdv is somewhat infrequent in the translation of elaboration (10.9\%) and result (5.4\%). The first meaning is rather vague or indeterminate, whereas a SubAdv is more meaning-defined, which might explain its low rate of usage. Concerning result, data reveal another preferred equivalent (see section 6.4.). In addition, only two instances have been found amongst the translations of illocutive G-P Adjuncts, and none preserves the source meaning.

With regard to the meaning-form interface, this group comprises both finite and non-finite SubAdvs, whose frequency of usage is quite even. Finite SubAdvs contain a typical, introductory subordinator or conjunction, the majority of which are semantically equivalent to the introductory particles of the English G-P Adjuncts (e.g., before - antes de). With regard to the non-finite SubAdv, most of them are infinitive clauses.

As observed with the G Adjunct, certain SubAdvs deviate semantically from their STs. Again, the reason might be a different interpretation as a result of a semantically indeterminate English G-P Adjunct (Kortmann 1991), as seen in the text pair (5):

(5) a. [...] which he had missed by finding himself forced to fly standby and entering in as it were medias res. Part_G-P Adjunct - Process

b. [...] que él se había perdido al verse obligado a volar stand-by y a entrar cuando este ya estaba in media res.

SubAdv - Cause

(ACTRES Parallel Corpus)

I would argue that there are two main aspects that contribute to the Spanish SubAdv being similar to the English G-P Adjuncts: first, it is a central syntagmatic option for expressing circumstantial meanings, and second, it is a dependent clause, sometimes non-finite, that adds on extra information within a matrix clause. Again, differences of meaning, on this basis of sameness, might arise as a result of the need for interpretation on the part of the translator.

\subsection{Simple clause}

The use of this Spanish resource as an equivalent is unexpectedly frequent. Its high frequency stems mainly from the fact that it is the most recurrent resource for translating G-P Adjuncts that convey elaboration (40\%), a function of which there are 403 instances. It ranks second as a TT of G-P Adjuncts that express result (21.1\%), third as an option for translating cause (8.5\%), concession (5\%), illocution (6.25\%) and condition (3.2\%), and it occupies the fourth position amongst the TTs of time $(18.8 \%)$ and process (7.9\%). Its share of usage is, however, lower when translating place $(6.25 \%)$ and especially purpose (1.6\%). Yet, it can realize any of the source semantic functions, which adds onto the ground of sameness between source and target resources.

It is unexpected because it would have been unlikely to foresee its use as an equivalent of the English G-P Adjunct. The main reason is that the simple clause is quite far from the English resource in the syntagmatic axis, as it matches neither the syntactic relations nor the semantic content, i.e., circumstantial, the English resource is usually associated with. In other words, whereas other resources might come to mind as possible expressive means of circumstantial meanings, this would not be the 
case with the simple clause. Seen from the point of view of language use, the simple clause is acceptable and complies with the lexico-grammatical rules of the TL. However, as a TT, equivalence relies not in the resource itself, as is the case with the G Adjunct or the SubAdv, but on the co(n)text where this resource has been actualized. In other words, it is possible to observe a relation between the simple clause as TT and its ST by relying almost entirely on the lexical content to be transferred (see example 6). As such, the type of equivalence that is displayed by such a translation pair is more lexical than functional. With regard to this, a terminological clarification needs to be made: by lexical equivalence or correspondence, I do not mean word-forword translation, but the fact that there are lexically-related items in either wording, i.e., source and target.

(6) a. Most bishops were efficient administrators of their dioceses, keeping their clergy up to the mark, or improving the local infrastructure with canals and roads.

b. La mayoría de los obispos eran administradores eficaces de su diócesis, mantenían la clerecía a la altura precisa, o mejoraban la infraestructura local con canales y caminos.

(ACTRES Parallel Corpus)

This TT is an instance of a translation shift, in Chesterman's sense (2005), which is in turn based on Venuti's (2002). This shift derives from the translator's need to solve a problem in the most naturally expressive way possible within the TL. The problem to be faced is that elaboration entails a great deal of indeterminacy and semantic overlap as it allows for various interpretations, such as clarification, addition or time-simultaneity. With regard to this, coordination, which ties up two independent - simple - sentences together seems to be a syntagmatically closer resource to express those connotations in an unmarked way.

\subsection{Prepositional Phrase (PP)}

With a lower share of usage, the PP is still considered one of the most recurrent and closer equivalents under the criteria that (a) it has been used for translating any of the original semantic functions except for condition, and (b) it would be placed fairly close to the ST in the syntagmatic axis of language, as the PP typically realizes circumstantial meanings in Spanish. One main difference between the PP and the Spanish G Adjunct or the SubAdv is that this option operates below the sentence level and not at the sentence level, as the other two do. Syntactically, this implies a rank shift.

The PP occupies the third position in order of frequency when translating process (10.1\%), elaboration (11.6\%), purpose (15\%) and place (18.75\%), and the fourth position when the ST conveys time (3.4\%), cause (6.2\%), and illocution (6.25\%). It is less frequently used for translating G-P Adjuncts that express result (0.6\%) and concession (2.4\%). An even distribution is also observed with regard to the presence or absence of an introductory particle in their STs.

As happens with other equivalents, the PP does not always keep up with semantic equivalence, there being occasional deviations. Along with the semantics, the PP might display another functional difference, this one related to the co-text of usage. The great majority of PPs found are, syntactically speaking, adverbials. There are 
some instances, however, of PPs functioning as noun adjacent, which is a resource traditionally associated with the realization of another semantic function, namely, direct, nominal characterization (Ramón García 2001). The parallel concordances (7) and (8) show two different uses of the same translational option.

(7) a. Using a blue ballpoint pen, Brian Nelson had made an obscene hole where her legs were crossed.

b. Con un bolígrafo azul, Brian Nelson había hecho un obsceno agujero donde se cruzaban las piernas.

$\mathrm{PP}=\mathrm{Adv}$ of Process

(ACTRES Parallel Corpus)

(8) a. I have a picture of myself standing there, caked in sand, hair blowing in the wind, gesticulating towards the sea.

b. Me viene a la mente la imagen de mí misma de pie en el camino, recubierta de arena y con el cabello al viento, gesticulando hacia el mar.

$\mathrm{PP}=$ Complement

(ACTRES Parallel Corpus)

It is believed that the type of usage seen in example (8) would mark a difference with respect to the ST, which diminishes the overall degree of functional equivalence between ST and TT. Yet, it is still easy to recognize a lexical correspondence between them. I would argue, then, that the equivalence relation holds on lexical components mainly. Furthermore, these examples bring to light (a) how dynamic meaning is, since the same forms might express considerably different ideas, and (b) how relevant co-text is to define the actual function of a linguistic form. Hence, the dynamic nature of functional equivalence is acted out as comprising various factors: semantics, syntax, and lexis, which are cornerstones of data interpretation in this study.

All the remaining equivalents will be considered peripheral according to the following criteria:

- They are infrequent or display a low share of usage;

- They are associated with only some of the source semantic functions;

- They are at a considerable distance from the ST in the syntagmatic axis.

The three criteria above refer to the overall realization of the translational options under consideration. As such, by low share of usage is understood no more than $5 \%$ of all the translated material. ${ }^{6}$ On the other hand, syntagmatic distribution is concerned with whether the Spanish translational options are typically used for conveying functions other than circumstantial meanings as documented by previous research.

A defining feature of the majority of these equivalents is unexpected. Moreover, most of them also trigger a shift in translation, which will focus part of our attention on differences too. Let us look more deeply into the nature of divergent similarity in order to measure equivalence.

\subsection{Relative clause}

This seems to work as an equivalent of six out of the ten semantic functions realized by the STs, with the exception of purpose, illocution, condition and place. It is clearly preferred when the ST is bare. Surprisingly enough, this option ranks third in the 
translation of G-P Adjuncts of result (15.7\%), which is likely due to the causative which that the STs conceal. Thus, the TTs are, formally, lo que or lo cual relative clauses. Most importantly, even though the relative clause is usually associated with the realization of other functions, it seems an acceptable way of expressing result, as this meaning is kept in almost all the instances found, as can be seen in example (9).

(9) a. This occurred when the surface pumps failed, leading to a catastrophic loss of pressure in the suit. [This occurred when the surface pumps failed, which lead to a catastrophic...]

b. Esto ocurría cuando fallaban las bombas de la superficie, lo que provocaba una pérdida catastrófica de presión en el traje.

(ACTRES Parallel Corpus)

It is also remarkably frequent as a TT of G-P Adjuncts that convey elaboration (8.4\%), which, according to Kortmann "add details to the matrix propositions, or some part of it, in order to contribute to its better understanding or to heighten the degree of its imagination by the hearer/reader" (Kortmann 1991: 166-167). The author seems to be hinting at a degree of characterization in the G-P Adjunct here, which might explain the amount of relative clauses as its TT.

\subsection{Nominal Subordinate Clause}

Almost all the semantic functions of English G-P Adjuncts have been translated into Spanish by means of a nominal subordinate clause, with the exception of illocution and condition. This equivalent occupies, however, the last positions in the frequency scale, except for place (18.75\%), where it stands second. It is more frequently used when the ST is equipped with an introductory particle. Overall, this equivalent results from a translation shift whereby the translator (re)codes the original message by introducing significant formal changes, so that the new functional resource is embedded in a rather different co-text. As the source function is not typical of the equivalent, since the latter is not a syntagmatic option to convey the former, I would argue that its degree of functional equivalence is far from high. However, it is a grammatically acceptable equivalent that works in the translation pair through lexical links.

(10) a. Russia has been encouraged to sign the Kyoto Protocol by making aid conditional on its ratification

b. La forma de animar a Rusia a firmar el Protocolo de Kioto ha sido ofrecerle una ayuda condicionada a su ratificación

(ACTRES Parallel Corpus)

In other words, the content of process entailed by the ST has been kept lexically through the word forma, which has been included by the translator as the referent of the subordinate clause.

This example shows clearly that shifts are not always a necessary solution to a problem, but the result of the translator's unconscious towards domestication (Venuti 2002). Having at their disposal more than one choice, translators may tend to use an option which might be well-received by the target culture. This is how Venuti understands shifts in terms of gaining in translation, rather than losses. In turn, this is a 
clear instance of the fact that divergent similarity is created by the translator (Chesterman 2007).

\subsection{Adverbial Phrase (AdvP)}

With the exception of result, all the meanings conveyed by English G-P Adjuncts are translated by means of the AdvP. Likewise, it is evenly used as a translation of both bare and particle-introduced Adjuncts. Syntactically speaking, the great majority of AdvPs found are adverbials, which strengthens their functional equivalence with the STs. Furthermore, most of them preserve the original meaning, as exemplified by (11), which adds onto the degree of functional equivalence.

(11) a. The instructions tell you to "condition" the slab by running hot water over it for a minute or so before using it each time, and again half-way through the thawing process.

b. Las instrucciones indican que deberá "acondicionar" la tableta sumergiéndola previamente en agua caliente durante un minuto aproximadamente cada vez que quiera usarla, y otra vez cuando el proceso de descongelación haya comenzado.

(ACTRES Parallel Corpus)

Despite these similarities, however, it is not a frequent equivalent. My interpretation of this is that translators, having at their disposal closer equivalents, prefer not to use an option that implies a down-rank shift whereby the TT no longer holds cotextual or syntactic exact similarity with the ST. Still, such an option would still be functionally equivalent, as happens with the PP, for both resources convey circumstantial meanings.

This phenomenon entails two interesting issues. First, even though the AdvP seems, a priori, a strong functional equivalent, its actual usage displays a low degree of functional equivalence in terms of typicality. And second, this is a clear instance of the directional nature of equivalence, which has to be measured when the translation is acted out, taking the ST function as the starting point for reference.

\subsection{Adjectival Phrase (AdjP)}

According to the data, the AdjP is equivalent to English G-P Adjuncts that express time $(0.6 \%)$, cause $(4.3 \%)$, process $(1.3 \%)$, elaboration $(3.7 \%)$ and result $(0.6 \%)$, and preferably when these are bare. Nevertheless, its usage does not display a high share in any of them. Whenever used, the function of the ST is rarely kept, which is somewhat expected, as the AdjP usually conveys characterization instead of circumstantial meanings. Greater similarity is observed with those STs conveying elaboration due to the meaning connotations mentioned above. Overall, however, the degree of equivalence is rather low. The textual pair (12) shows an example of this.

(12) a. Rejoicing in Heidegger's seeming intimacy, Husserl can have had no inkling of these dismissals.

b. Tan contento con la aparente intimidad de Heidegger, es posible que Husserl ni se imaginara estas renuncias. 


\subsection{Characterizing $G$}

There exists in Spanish one type of G constructions whose overall function is to characterize noun phrases (NPs) either directly or indirectly. In the latter case, some of these $\mathrm{G}$ constructions might convey circumstantial meanings of process and time, which are nevertheless realized by means of interplay between the $\mathrm{G}$ and the co-text which surrounds it. There are certain occurrences of this resource as an equivalent of bare G-P Adjuncts that express time ( $0.7 \%)$, process $(0.2 \%)$, elaboration $(6.45 \%)$, result $(0.3 \%)$ and purpose $(1.6 \%)$. It is rather peripheral in all of them, likely due to the functional loss it implies, as seen in example (13):

(13) a. All the same I went away already buzzing with ideas and everything suddenly seemed a lot easier.

b. Me marché con un montón de ideas rondándome ya en la cabeza y todo me pareció de repente mucho más fácil.

(ACTRES Parallel Corpus)

\subsection{Noun Phrase (NP)}

Except for place, condition and illocution, the remaining source semantic functions display an NP amongst their equivalents. Its frequency of use with respect to there being a particle in the ST or not is quite even. There are, however, a few instances, and all of them imply the type of functional loss reported upon in the previous paragraphs. Example (14) shows how the equivalence relation is to be drawn from lexical correspondences mainly.

(14) a. [...] he rammed his fist into a pane, matching the determination of Junior's hand in his jeans.

b. [...] rompió un cristal de un puñetazo, su determinación en consecuencia con la de la mano de Junior en sus téjanos.

(ACTRES Parallel Corpus)

\subsection{Infinitive}

There are very few instances amongst the translation of time $(0.07 \%)$, process $(0.35 \%)$ and elaboration (3.9\%) G-P Adjuncts. Infinitive clauses do not typically convey the type of function realized by adjuncts. They usually display a more nominal function, such as an apposition as shown in example (15).

(15) a. One can maintain one's adolescent rebelliousness (smoking pot, hanging out, ignoring all responsibility, not to mention all moral constraint) and remain free.

G-P Adjunct - Process

b. La primera es conservar la rebeldía juvenil (fumar hierba, tomar copas, rechazar los compromisos y consideraciones éticas) y seguir siendo libres.

Apposition

(ACTRES Parallel Corpus)

The ST clearly expresses the way in which adolescent rebelliousness is maintained, by giving examples of how this is materialized. In other words, processes of 
rebelling. On the other hand, the translation lists examples of what rebelliousness might imply. The notion of equivalence is attained by looking at further co-text, where this list refers back to the various ways (formas) of rebelliousness. This example, thus, sheds light on the need to assess equivalence in co(n)text.

\subsection{Adversative clause}

This option has been found amongst the TTs of English G-P Adjuncts expressing time $(0.07 \%)$ (both with and without an introductory particle), result (bare) $(0.3 \%)$ and contrast (with particle) $(4.8 \%)$. It is in the translation of the latter that its share of usage is slightly higher, which might be due to their semantic similarity, for both resources add concessive connotations to what has been said previously. Syntactically, the relation is different, though, for the ST is embedded within a main clause, whereas the adversative clause is considered coordinated, but autonomous. This is clearly seen in example (16).

(16) a. Nagging her every second, but doing it: airing, cleaning, spooning, rubbing.

b. La importunaba a cada momento, pero lo hacía: airear, limpiar, dar de comer.

(ACTRES Parallel Corpus)

\subsection{Participle clause}

There are a few occurrences distributed amongst the TTs of STs that realize time (1.1\%), elaboration $(0.2 \%)$ and cause $(0.5 \%)$. These STs are always bare.

(17) a. Sitting there, Junior felt the kick of being, living, in a house, a real house, her first.

b. Allí sentada, Júnior experimentó la emoción de estar, de vivir en una casa, una auténtica casa, la primera para ella.

(ACTRES Parallel Corpus)

\subsection{Locution}

This is the least used option of the whole sample, although it ranks second as the TT of English G-P Adjuncts that express illocution (0.07\%) due to the disposal of idioms with the same illocutionary force in Spanish, as seen in example (18).

(18) a. Generally speaking, Arendt's broad condemnation of the Jewish leadership displayed little comprehension...

b. En términos generales, la condena general de la dirección judía que hace Arendt mostró poca comprensión por...

(ACTRES Parallel Corpus)

There is a set of English G-P Adjuncts of illocution, fairly easy to recognize, that could be understood as fixed expressions with a metatextual function. As such, the idiomatic equivalents in the Spanish translations could be the closest equivalent, as they both would realize the same function within the same semiotic domain of language. This would provide further evidence for the fact that high frequency does not necessarily equal higher equivalence. 
Concerning the so-called peripheral equivalents, some regularities can be established: 1) the degree of functional equivalence, as comprising semantics, syntax and lexis, is lower as compared with the so-called recurrent equivalents; 2) out of these components, lexical equivalence is usually the one holding ST and TT together; 3) syntactic shifts are common, as a result of a decrease in syntagmatic proximity; 4) as a consequence of the meaning-form interface, syntactic shifts carry semantic loss too; 5) bearing all this in mind, it seems that the differences in translation outnumber the similarities, as they neither match paradigmatically nor belong to the same syntagmatic axis.

Having completed the contrastive analysis between English G-P Adjuncts and Spanish on a basis of similarity, we can now provide an answer to the first question regarding the differences displayed in this cross-linguistic relation of equivalence. Such differences entail meaning deviations and formal distance mainly, as observed through the loss of semantic and syntactic losses reported upon.

\section{Measuring equivalence}

According to Malmkjaer, "translation is an excellent way of discovering relationships between languages, particularly to demonstrate their similarities or to suggest a common semantic base underlying their surface differences" (Malmkjaer 2005: 13). Hence, both similarities and differences are necessary to account for translation equivalence, as has been commented upon in the preceding sections. Establishing a clear-cut boundary between degrees of functional equivalence is not an easy task, due to the inherent fluctuation of equivalence, which necessarily prevents fixed boundaries. Furthermore, these would challenge the dynamic nature of functional equivalence so it is rather undesirable. Yet, looking at the behaviour of the various equivalents provided by translated language, it is feasible to classify them in terms of how close they are to their STs within a functional perspective. As a way of answering the second question concerning how equivalence is attained, let us attempt a grading system of functional equivalence with regard to the following parameters:

- Perceived similarity, where three types are distinguished: assumed (A), expected (E) and unexpected $(\mathrm{U})$.

- Frequency, ranging from recurrent $(\mathrm{R})$ to peripheral $(\mathrm{P})$ equivalents.

- Semantic function, where three situations might arise: 1) the TT keeps the same function (S); 2) the TT keeps the same function, but there are semantic deviations $(\mathrm{S}+\mathrm{D})$, and 3) the TT has a different semantic function (D).

- Syntagmatic nature, whereby the TT might belong to the same syntagmatic axis (S) or not (D).

- Lexical correspondence: this parameter refers to lexicographical evidence for relation between ST and TT, and will be indicated with a plus symbol (+) if kept.

Table 2 illustrates this gradation system as applied to the equivalent items identified from the study. In order to control for some overlapping, I will use lower letter case or capitals to indicate what the governing trend is. 
TABLE 2

Usage-based parameters for grading functional equivalence

\begin{tabular}{|c|c|c|c|c|c|c|c|c|c|c|c|}
\hline \multirow{2}{*}{ Equivalents } & \multicolumn{3}{|c|}{$\begin{array}{l}\text { Perceived } \\
\text { similarity }\end{array}$} & \multicolumn{2}{|c|}{ Frequency } & \multicolumn{3}{|c|}{ Meaning } & \multicolumn{2}{|c|}{$\begin{array}{c}\text { Syntagmatic } \\
\text { axis }\end{array}$} & \multirow[t]{2}{*}{$\begin{array}{c}\text { Lexical } \\
\text { correspondence } \\
\end{array}$} \\
\hline & A & $\mathrm{E}$ & $\mathrm{U}$ & $\mathrm{R}$ & $\mathrm{P}$ & S & $\mathrm{S}+\mathrm{D}$ & $\mathrm{D}$ & Ss & Ds & \\
\hline G Adjunct & \multicolumn{3}{|c|}{ A } & \multicolumn{2}{|c|}{$\mathrm{R}$} & \multicolumn{3}{|c|}{ S+d } & \multicolumn{2}{|c|}{$\mathrm{S}$} & + \\
\hline SubAdv & \multicolumn{3}{|c|}{ E } & \multicolumn{2}{|c|}{$\mathrm{R}$} & \multicolumn{3}{|c|}{$S+d$} & \multicolumn{2}{|c|}{ S } & + \\
\hline Simple cl & \multicolumn{3}{|c|}{$\mathrm{U}$} & \multicolumn{2}{|c|}{$\mathrm{R}$} & \multicolumn{3}{|c|}{$s+D$} & \multicolumn{2}{|c|}{$\mathrm{D}$} & + \\
\hline $\mathrm{PP}$ & \multicolumn{3}{|c|}{ E } & \multicolumn{2}{|c|}{$\mathrm{R}$} & \multicolumn{3}{|c|}{$S+d$} & \multicolumn{2}{|c|}{$\mathrm{S}^{*}$} & + \\
\hline Relative $\mathrm{cl}$ & \multicolumn{3}{|c|}{$\mathrm{U}$} & \multicolumn{2}{|c|}{$\mathrm{P}$} & \multicolumn{3}{|c|}{$s+D$} & \multicolumn{2}{|c|}{$\mathrm{D}$} & + \\
\hline Sub Nominal & \multicolumn{3}{|c|}{$\mathrm{U}$} & \multicolumn{2}{|c|}{$\mathrm{P}$} & \multicolumn{3}{|c|}{$s+D$} & \multicolumn{2}{|c|}{$\mathrm{D}$} & + \\
\hline AdvP & \multicolumn{3}{|c|}{ E } & \multicolumn{2}{|c|}{$\mathrm{P}$} & \multicolumn{3}{|c|}{$S+d$} & \multicolumn{2}{|c|}{$S^{*}$} & + \\
\hline AdjP & \multicolumn{3}{|c|}{$\mathrm{U}$} & & & & $\mathrm{D}$ & & & & + \\
\hline Characterising G & & $\mathrm{U}$ & & & & & $\mathrm{D}$ & & & & + \\
\hline NP & & $\mathrm{U}$ & & & & & $\mathrm{D}$ & & & & + \\
\hline Infinitive & & $\mathrm{U}$ & & & & & $\mathrm{D}$ & & & & + \\
\hline Adversative cl & & $\mathrm{U}$ & & & & & $s+D$ & & & & + \\
\hline Participle cl & & $\mathrm{U}$ & & & & & $S$ & & & & + \\
\hline Locution & & $\mathrm{E}$ & & & & & $S$ & & & & + \\
\hline $\begin{array}{l}\mathrm{A}=\text { Assumed } \mathrm{E}=1 \\
\mathrm{R}=\text { Recurrent } \mathrm{P}= \\
\mathrm{S}=\text { Same function } \\
\mathrm{S}+\mathrm{D}=\text { Same funct } \\
\mathrm{D}=\text { Different funct } \\
\mathrm{Ss}=\text { Same syntagm } \\
\text { Ds = Different synt } \\
\text { * There is a down }\end{array}$ & $\begin{array}{l}\text { on by } \\
\text { on } \\
\text { ic a } \\
\text { mat }\end{array}$ & sen & tip & leviat & & & & & & & \\
\hline
\end{tabular}

The closest equivalent would be the G Adjunct, followed by the SubAdv and the PP and AdvP. Whereas the perceived similarity between the English G-P Adjunct and the Spanish G Adjunct is obviously stronger, I would dare to say that the SubAdv could also be considered a near convergent equivalent, as the common ground shared by both resources is practically the same, as illustrated in Table 2 . The main difference is that the former is assumed, whereas the latter is not. Keeping the adverbial function and circumstantial contents realized by the STs in mind, it makes sense to expect a $\mathrm{PP}$ as a TT, for this resource is associated with this type of functions, amongst many others. As a translation unit, G-P Adjunct and PP operate on different levels of syntax, which involves diverging co-texts of functional realization. This makes it an option of a lower degree of equivalence by comparison with the other two. With regard to the AdvP, its degree of similarity with the source item is higher than that displayed by the simple clause, for example, as commented upon (see section 6). That is why I would move it closer in the similarity scale even if its actual usage as an equivalent is rather infrequent.

A few semantic deviations have been observed when resorting to all these equivalents, which are, nonetheless, a further component of functional equivalence. I have already mentioned the source of such deviations, which nevertheless function acceptably well within the target audience.

In relation to the remaining options, their use is not significantly recurrent. All of them, with the exception of the AdvP, are unexpected and they fail at maintaining 
functional similarity straight away, which diminishes considerably their actual degree of equivalence.

\section{Conclusions}

This study has been an attempt to deal with equivalence not so much in theory, but in actual practice by somehow disseminating its components and describing their interplay. For that, both the similarities and differences observed in the translation of English G-P Adjuncts into Spanish have been described considering semantic, syntactic and lexical issues, as these are building blocks of a functionalist approach to language use. The study also tries to show the importance of going interdisciplinary and flexible in the management of concepts and terms, although it is necessary to decide on the direction of analysis. The use of perceived similarity, a contrastivefunctional-analysis term, as a starting point for describing functional equivalence has proved useful to suggest a gradation system of equivalence that might, in turn, show different types of equivalence.

With regard to methodology, parallel corpora serve well to do research into equivalence patterns, and especially to observe different types of similarity. As Malmkjaer states, "for every (sanctionable) TT-ST item pair there will be one instantiation of translation equivalence. But for every such pair, other possible equivalence relationships exist" (Malmkjaer 2005: 3). As such, it is by looking at actual translations that these other equivalence relationships can be studied, as just shown. The first part of Malmkjaer's quotation might well refer to convergent similarity, whereas the second part makes room for divergent similarity.

To conclude, I believe the relevance of the study to be twofold: on the one hand, the similarities and differences examined make up a repository of equivalent resources from which translators could choose for future applications. The usefulness of this information would be guaranteed if it was appropriately rephrased as description-based, usable guidelines on how to search for higher equivalence in EnglishSpanish translation (Rabadán 2008). On the other hand, the insights gained might well contribute to the theoretical understanding of the notion of equivalence, in particular, and translation in general.

\section{NOTES}

* This reasearch was undertaken during the author's affiliation to the Universidad de León.

1. The term contrastive linguistics is nowadays more widely used than contrastive analysis. However, in order to avoid confusion with that of corpus linguistics, I will use the acronym CA.

2. For more information, check the research team's website at $<$ http://actres.unileon.es/ $>$.

3. The reader should not understand source and target text literally in the sense of a text being a unified whole with a standard rhetoric structure regarding its function. Rather, by source text and target text it is here understood pieces of text where the units under study are found. Due to the nature of the object of study, such units might be sentences or sentence constituents.

4. Italics added by the author.

5. There is a demo for free consultation on the ACTRES website: <http://actres.unileon.es/inicio. php? elementoID $=12>$.

6. Figures referring to the usage of translation options per semantic function will obviously differ and might well be superior to $5 \%$, which should be kept in mind so as to avoid confusion. 


\section{REFERENCES}

CATFORD, John Cunnison (1965): A Linguistic Theory of Translation. London: Oxford University Press.

Chesterman, Andrew (1998): Contrastive Functional Analysis. Amsterdam/Philadelphia: John Benjamins Publishing Company.

Chesterman, Andrew (2005): Problems with Strategies. In: Krisztina KÁroly and Agota Foris, eds. New Trends in Translation Studies. In Honour of Kinga Klaudy. Budapest: Akadémiai Kiadó, 17-28.

Chesterman, Andrew (2007): Similarity Analysis and the Translation Profile. In: Willy Vandeweghe, Sonia Vandepitte and Marc Van de Velde, eds. The Study of Language and Translation. Amsterdam/Philadephia: John Benjamins Publishing Company, 53-66.

Huddleston, Randolph and Pullum, Geoffrey K. (2002): The Cambridge Grammar of the English Language. Cambridge: Cambridge University Press.

Izquierdo, Marlén (2008): Estudio Contrastivo y de Traducción de las construcciones de -ing inglesas y sus equivalentes en español. Doctoral thesis, unpublished. León: University of León.

Izquierdo, Marlén, Hofland, Knut and Reigem, Øystein (2008): The ACTRES Parallel Corpus: an English-Spanish Translation Corpus. Corpora. 3:31-41.

Kortmann, Bernd (1991): Free Adjuncts and Absolutes in English. Problems of control and interpretation. London/New York: Routledge.

Krzeszowski, Tomasz P. (1990): Contrasting Languages. The Scope of Contrastive Linguistics. Berlin: Mouton de Gruyter.

MALMKJAER, Kirsten (2005): Linguistics and the Language of Translation. Edinburgh: Edinburgh University Press.

NidA, Eugene (1964): Toward a Science of Translating: With Special Reference to Principles and Procedures Involved in Bible Translating. Leiden: E. J. Brill.

Pym, Anthony (2007): Natural and directional equivalence in theories of translation. Target. 19(2):271-294.

Rabadán, Rosa. (2008): Refining the idea of "applied extensions." In: Anthony Pym, Miriam Shlesinger and Daniel Simeoni, eds. Beyond Descriptive Translation Studies. Investigations in homage to Gideon Toury. Amsterdam/Philadelphia: John Benjamins Publishing Company, 103-117.

RAMón García, Noelia (2001): Estudio contrastivo inglés-español de la caracterización de sustantivos. Doctoral thesis, unpublished. León: Universidad de León.

Tognini-Bonelli, Elena (2002): Corpus Linguistics at work. Amsterdam/Philadelphia: John Benjamins Publishing Company.

Toury, Gideon (1995): Descriptive Translation Studies and Beyond. Amsterdam/Philadelphia: John Benjamins Publishing Company.

Venuti, Lawrence. (2002): The difference that translation makes: the translator's unconscious. In: Alessandra RicCARDI, ed. Translation Studies - Perspectives on an Emerging Discipline. Cambridge: Cambridge University Press, 214-241. 